\title{
DETERMINING A RELATIONSHIP IN THE NATURE OF MARRIAGE: THE IMPACT OF RUKA ON THE DEPARTMENT OF WORK AND INCOME'S CONJUGAL STATUS POLICY
}

Jessica Wiseman*

In the 1997 case of Ruka v Department of Social Welfare, the Court of Appeal altered the test for determining whether a relationship was "in the nature of marriage" for the purposes of the Social Security Act 1964. In this article, the author analyses the impact of the decision on Department of Work and Incomes practice and on the subsequent decisions of the Social Security Appeal Authority. The author questions whether either Department or Appeal Authority has significantly altered their policy in light of the test adopted by the majority in Ruka. In light of its practical application, the author then critically accesses the test in Ruka and concludes that the general approach favoured by previous decisions of the High Court, and apparently continued by the Department subsequent to Ruka, is preferable.

\section{INTRODUCTION}

Ruka $v$ Department of Social Welfare ${ }^{1}$ is the leading case on the determination of "relationships in the nature of marriage" (colloquially referred to as "de facto relationships") in the context of the Social Security Act 1964. Prior to Ruka, the leading cases were Excell $v$ Department of Social Welfare ${ }^{2}$ and Thompson $v$ Department of Social

\footnotetext{
* This paper was submitted in fulfillment of the LLB(Hons) requirements at Victoria University of Wellington, 2000.

1 Ruka v Department of Social Welfare [1997] 1 NZLR 154 (CA) [Ruka].

2 Excell v Department of Social Welfare [1991] NZFLR 241 (HC) [Excell].
} 
Welfare. ${ }^{3}$ Excell and Thompson are characterised by weighing a range of factors, followed by an overall assessment as to whether the relationship is in the nature of marriage. Ruka changed the test by making financial interdependence, together with emotional commitment, essential.

It has been said it is easier to recognise a de facto relationship than to define one. ${ }^{4}$ This problem is addressed in the Social Security Act by section 63(b), which gives the chief executive of the Department of Work and Income the discretion to "regard as husband and wife any man and woman who, not being legally married, have entered into a relationship in the nature of marriage". 5

The discretion is delegated under section 10(1) to officers of the Department, including frontline staff, who make the initial evaluation about an applicant's conjugal status. Exercise of the discretion is governed by the Department's conjugal status policy. Section 63 also confers a discretion to determine when an applicant entered into a relationship, and to grant or refuse to grant a benefit, or terminate, reduce, or increase any benefit already granted, from that date accordingly. The assessment is to be made on a "purely objective basis" (the words "in the opinion of the Commission" having been removed). ${ }^{6}$

Conjugal status affects eligibility for benefits. A person who is legally married or living in a relationship in the nature of marriage is not eligible for the domestic purposes ${ }^{7}$ or widows' benefits. Conversely, a woman is eligible for the widows' benefit if the relationship with her deceased partner was in the nature of marriage. ${ }^{8}$ For other benefits, such as the unemployment benefit or student allowances, the combined income of both partners is taken into account when assessing eligibility. ${ }^{9}$ The objective of section 63(b) "is to ensure that unmarried couples who enter into a relationship akin to marriage are not

3 Thompson $v$ Department of Social Welfare [1994] 2 NZLR 369 (HC) [Thompson].

4 See for example William R Atkin Living Together Without Marriage (Butterworths, Wellington, 1991) 13.

5 A married beneficiary may be regarded as unmarried if they are "living apart" from their wife or husband under s 63(a).

6 Thompson, above n 3, following Social Security Appeal Authority Decision No 567 (1980) 2 NZAR 565.

7 Except where they care for a sick or infirm person at home: Social Security Act 1964, s 27G.

8 Social Security Act 1964, s 21(2D).

9 If eligible, the benefit is paid at the married rate, which is less than the amount paid to two single people as it takes into account the economies of scale available to a married couple. 
treated more favourably for benefit purposes than those who are legally married." 10 It is crucial, therefore, to determine whether a beneficiary is living in a relationship in the nature of marriage.

The phrase is not defined in the legislation, however, and it is well recognised in the cases that defining it is no simple task. ${ }^{11}$ The Marriage Act 1955 requires legal marriages to be created by the observance of formalities ${ }^{12}$ and prohibits certain relationships. ${ }^{13}$ By contrast, de facto relationships typically have no clear beginning, ${ }^{14}$ and the types of relationship a person may enter into are regulated only by the criminal law, such as the law relating to incest and minors.

For guidance in interpreting the phrase, officers rely on Department policy manuals, which are informed by case law and Department practice.

In response to criticism that the Department policy is outdated, it has been revised recently to reflect the law more accurately. I will suggest, however, that in practice the changes are not as great as some commentators would argue are warranted. I will consider the way Ruka differs from Excell and Thompson, then analyse the Department's conjugal status policy and how it has changed since Ruka. I will then discuss the application of Ruka in Social Security Appeal Authority decisions. I will identify some problems with the focus on financial interdependence in $R u k a$, and suggest that it may, after all, be preferable to determine the nature of a relationship by making an overall assessment of various factors, and asking whether the parties have "so merged their lives" that it can be said their relationship is in the nature of marriage.

10 Ruka, above n 1, 181 per Thomas J; echoing Tipping J in Thompson, above $\mathrm{n} 3,374$. Section 63 does not apply to same-sex relationships. Applicants in same-sex relationships may therefore be supported by a partner and also receive a benefit, and conversely, be ineligible for other benefits. Although this seems outdated and inequitable, extending the policy to include same-sex relationships would require amending the Social Security Act, as s 63(b) expressly refers to "any man and woman".

11 See for example Lichtenstein $v$ Lichtenstein (1986) 4 NZFLR 25 (HC).

12 A licence must be obtained and the marriage must be solemnised by a marriage celebrant: Marriage Act 1955, s 21.

13 Marriage Act 1955, 2nd Schedule.

14 Nor do they necessarily have a clear ending; compare the formal procedures required to dissolve a marriage: Family Proceedings Act 1980. 


\section{IMPACT OF RUKA ON THE DEFINITION OF A "RELATIONSHIP IN THE NATURE OF MARRIAGE"}

\section{A High Court}

In Excell, a legally married couple were found to be "living together" under section 27B of the Social Security Act, but the case was argued as if the test was whether they had entered into a relationship in the nature of marriage. ${ }^{15}$ Fisher J summarised the "core elements of cohabitation" as: a "mental commitment to live together as husband and wife and a manifestation of that commitment by conduct", with no minimum period; "the cumulative quality, quantity, continuity and duration" of factors indicating a relationship; 16 "indicia" including (but not limited to) "pooling of labour and financial resources" and "provision of financial assistance", shared dwelling, "emotional dependence and support", shared household activities; and the duration of the relationship and "signs of permanence for the future". ${ }^{17}$ Finally, "a broad value judgment is required". ${ }^{18}$

In Thompson, Tipping J said, "[i]nherent in the concept of a relationship in the nature of marriage are both mental and physical aspects", and the physical aspects should usually be considered first. ${ }^{19}$ Ten aspects are listed, similar to Fisher J's indicia in Excell. Sharing "costs and other financial responsibilities by the pooling of resources or otherwise" is seventh on the list. ${ }^{20}$ Sometimes other factors will also "require assessment in the overall picture", and the "ultimate decision will always be one of fact and degree." 21 The "mental ingredient" comprises "some commitment by the parties to their relationship ... for the foreseeable future. Any lesser commitment would ... be neither sufficient for nor consistent with a relationship in the nature of marriage". ${ }^{22}$ The "flavour of the essential issue" can then be "captured by asking whether the parties have so merged their lives, for

15 This did "full justice to the appellant", as "it is easier for the prosecution to demonstrate that a legally married couple are 'living together' than to demonstrate that a couple who are not legally married have entered into a relationship in the nature of marriage": Excell, above n 2, 246. Compare Tipping J in Thompson, above n 3, 372: "[L]iving apart is not necessarily the exact corollary of entering into a relationship in the nature of marriage. Some guidance can however be obtained from the reverse side of the coin, provided care is taken."

Excell, above n 2, 248

17 Excell, above n 2, 248.

Excell, above n 2, 248

19 Thompson, above n 3, 373.

Thompson, above n 3, 373

21 Thompson, above n 3, 373.

22 Thompson, above n 3, 374. 
the time being, that they are, for all practical purposes, living together as a married couple." 23 Finally, "the ultimate question must be answered in a broad practical way and in a manner consistent with the object of $\mathrm{s} 63^{\prime \prime} .^{24}$

\section{B Social Security Appeal Authority}

A beneficiary may dispute a section 63(b) determination by applying under section $10 \mathrm{~A}$ of the Social Security Act to have the determination reviewed by the Benefits Review Committee. The beneficiary also has a right of appeal under section 12J to the Social Security Appeal Authority, an independent tribunal. The Appeal Authority's decisions are important because most beneficiaries do not have the resources to appeal from there to the High Court, unless they obtain legal aid. Moreover, appeals to the High Court are on questions of law only. ${ }^{25}$ Appeal Authority decisions prior to Ruka clearly show Excell and Thompson being applied.

For example, in Decision 75/96, the Authority said "reliance must be made upon the High Court decision of Excell" in section 63(b) cases, and the Authority members agreed with Fisher J's proposition that it is the "cumulative effect of various items ... which assist in the determination of whether a relationship in the nature of marriage exists." 26 The Authority looked at indicators such as shared accommodation and domestic tasks, shared finances, outside activities and trips together. The appellant said there was no sexual relationship or commitment for the future, but following Excell, the Authority said "simply because one aspect was lacking" did not mean there was no relationship in the nature of marriage, ${ }^{27}$ and "[o]n balance we hold that the cumulative effect of the factors we have listed ... are such as to outweigh the other matters that we have referred to." 28

\section{Ruka}

In Ruka the Court of Appeal re-examined the phrase "relationship in the nature of marriage". Both the majority judgments (Blanchard J and Richardson P in a joint judgment delivered by Blanchard J, and Thomas J) and the dissenting judgment (Henry and Gault JJ in a joint judgment delivered by Henry J) referred to the "checklist" approach which may be discerned from Thompson, and acknowledged that lists of relevant factors may be

\footnotetext{
23 Thompson, above $\mathrm{n} 3,374$.

24 Thompson, above n 3, 374.

25 Social Security Act 1964, s 12Q.

26 Decision 75/96 (24 July 1996) Social Security Appeal Authority (Latham, Dell, Morgan) 3.

27 Decision 75/96, above n 26, 3.

28 Decision 75/96, above n 26, 5-6.
} 
helpful in some cases. ${ }^{29}$ Considering the purpose of the Social Security Act, however, the majority reformulated the test. They found that the Act's "emphasis on loss of financial support" 30 meant that "financial interdependence" between the parties was crucial: ${ }^{31}$

[A] relationship in the nature of marriage for the purpose of the Social Security Act is one in which an essential element is that there is an acceptance by one partner that (to take the stereotypical role) he will support the other partner and any child or children of the relationship if she has no income of her own or to the extent that it is or becomes inadequate. The commitment must go beyond mere sharing of living expenses, as platonic flatmates or siblings living together may do; it must amount to a willingness to support, if the need exists. There must be at least that degree of financial engagement or understanding between the couple. It will not, however, be negated by a refusal to support, or an arrangement that support will not be given, which is motivated by the knowledge that the dependent partner will then be able to claim a benefit. Such a stratagem cannot create a genuine absence of support.

In addition to financial interdependence, emotional commitment is required: ${ }^{32}$

Where financial support is available nevertheless there will not be a relationship in the nature of marriage for this purpose unless that support is accompanied by sufficient features evidencing a continuing emotional commitment not arising just from a blood relationship. Of these, the sharing of the same roof and of a sexual relationship (especially if it produces offspring) are likely to be the most significant indicators.

Thomas J agreed with the approach of the other majority judges, but seemed to reverse the emphasis: ${ }^{33}$

[T] here must be a mutual commitment on the part of the parties to so merge their lives that it can be said that they have assumed responsibility for each other and .... in the context of the Social Security Act, a heavy emphasis must be placed on the need for an assumption of financial responsibility or interdependence as part of that commitment.

To summarise, where the "key positive features which are to be found in most legal marriages which have not broken down (cohabitation and a degree of companionship

29 Ruka, above n 1, 161 per Blanchard J; 165 per Henry J; 184 per Thomas J. Henry J points out that Tipping J did not necessarily purport to provide a checklist.

30 Ruka, above $\mathrm{n} 1,161$ per Blanchard J.

31 Ruka, above $\mathrm{n} 1,161$ per Blanchard J.

32 Ruka, above n 1, 161-162 per Blanchard J.

33 Ruka, above $\mathrm{n} 1,185$ per Thomas J. 
demonstrating an emotional commitment)" are "found together with financial interdependence there will be such a merging of lives as equates for the purposes of the legislation to a legal marriage." 34

The majority said "it may be necessary to accept that the phrase 'relationship in the nature of marriage' need not have the same meaning in different statutes". ${ }^{35}$ The minority, however, could "see no reason to give the phrase as it is used in the Social Security Act 1964 other than its ordinary meaning."36 They argued against a "restrictive construction" of the phrase, as accepting Ruka's submissions "would effectively take away rights which she and others in a like situation would otherwise have under the Act, and probably also under other legislation." 37

The minority said determining whether a relationship has "the essential character of a marriage", "will require an objective commonsense assessment of the factors which go to make up the particular relationship". ${ }^{38}$ Factors could include "joint living arrangements, an emotional and sexual relationship, duration, the creation of a family, the pooling of financial resources, the sharing of property, responsibilities and social activities", among others. ${ }^{39}$ For the minority, therefore, financial interdependence and emotional commitment were relevant but not determinative factors.

Isabella Ruka was convicted of benefit fraud in both the District Court and the High Court, ${ }^{40}$ on the basis that she had fraudulently obtained benefits by wilfully omitting to tell the Department that she was living with a Mr T. She defended the charges on the ground that she was suffering from "battered woman's syndrome", and therefore lacked intent to defraud the Department. This defence was rejected in both the lower courts, and

34 Ruka, above $\mathrm{n} 1,162$ per Blanchard $\mathrm{J}$.

35 Ruka, above n 1, 183 per Thomas J; see also 162 per Blanchard J. Fisher J recognised this in Excell, above $n 2,248$

36 Ruka, above n 1, 165 per Henry J.

37 Ruka, above n 1, 165 per Henry J. For example, if $\mathrm{T}$ had died, Ruka would not have been eligible for the widows' benefit. However, she would have been eligible for the domestic purposes or unemployment benefit, so the problem envisaged by Henry J may not matter in practical terms. See also Part III B 3 for a discussion of eligibility for protection under the Domestic Violence Act 1995.

38 Ruka, above n 1, 165 per Henry J.

39 Ruka, above n 1, 165 per Henry J.

40 Under the Social Security Act 1964, s 127, and the Crimes Act 1961, s 229A. 
was not argued in the Court of Appeal; however the majority said a battering relationship could negative factors which would otherwise indicate an emotional commitment. ${ }^{41}$

Barker J in the High Court "took as his starting point the list formulated by Tipping J in Thompson". ${ }^{42}$ He noted the aspects of Ruka's relationship which indicated it was in the nature of marriage: they had lived together for over 14 years; they had a child and moved cities together; they shared a bedroom and a sexual relationship (although it was violent and non-consensual); they sometimes socialised together; and they presented to outsiders as a family unit. Barker $\mathrm{J}$ set against these indicia the aspects which might indicate the absence of a relationship in the nature of marriage: T's continual violence towards Ruka; lack of financial support; lack of emotional dependence; T's limited parental involvement; and T's relationships with other women. ${ }^{43}$

Barker J considered they were sufficiently committed to the relationship, so the "mental ingredient" identified by Tipping J in Thompson was present. However, both the majority judgments in the Court of Appeal noted the "inconsistency"44 in Barker J's finding that Ruka "elected to continue with the relationship" even though she was "trapped" by T's violence and threats to kill her if she left. ${ }^{45}$

For the majority, the clear lack of financial support, which was not the result of an "arrangement" between the two ${ }^{46}$ coupled with the absence of an emotional commitment, meant that Ruka had not been living in a relationship in the nature of marriage with $\mathrm{T}$, and the convictions were quashed.

III DEPARTMENT OF WORK AND INCOME CONJUGAL STATUS POLICY

\section{A Department Policy Prior to Ruka}

When Ruka was decided, the relevant chapter in the Department policy manual, Core Topics, had last been revised in February 1994. ${ }^{47}$ Updates and circulars added to, rather than replaced, outdated policy information. ${ }^{48}$

41 Ruka, above $\mathrm{n} 1,158$ per Blanchard J; 182 per Thomas J.

42 Ruka, above $\mathrm{n} 1,178$ per Thomas $\mathrm{J}$.

43 Ruka, above $\mathrm{n} 1,178$ per Thomas $\mathrm{J}$.

44 Ruka, above $\mathrm{n} 1,160$ per Blanchard J; 179 per Thomas J.

45 Barker J quoted in Ruka, above n 1, 179 per Thomas J (emphasis added by Thomas J).

46 See Blanchard J's statement in the quote accompanying $\mathrm{n} 31$.

47 "Marital Status for Benefit Purposes" in Core Topics (Income Support Service manual, July 1996) ["Core Topics"]. 
The influence of Excell and Thompson is clear. The manual directs officers to consider factors such as shared dwelling and household activities, emotional support and dependence, pooled financial resources, ${ }^{49}$ exclusive sexual relationship, shared leisure and social activities, shared parental obligations, and presentation as a couple to outsiders. At the end of the list, the manual almost quotes Excell: "The decision cannot be based on the absence or presence of any one single factor. It is the quality, quantity, continuity and duration of all the factors found to exist that matters." 50 Guidelines, comprising questions for applicants, help officers determine whether and to what extent the factors exist. ${ }^{51}$ For example, officers might ask an applicant how many nights per week they spend with their partner, or whether the partner disciplines the applicant's child. A woman might be asked if she is known by her partner's name. Other questions, such as whether the applicant uses their partner's car, who pays the rent, and in whose name the tenancy is held, were added in an update. ${ }^{52}$ According to that update: ${ }^{53}$

The most reasoned viewpoint remains that no one factor by itself can constitute the establishment of a relationship and, no absence of a factor can be considered as determining a relationship. No list that attempts to determine what constitutes a relationship could ever be exhaustive.

\section{B Department Response to Ruka}

\section{Initial response}

Departmental policy was updated following Ruka, based on a Crown Law opinion on the implications of the judgment. ${ }^{54}$ The Department considers that its policy did not change significantly, as officers were already applying financial and emotional

48 Interview with Kirsty Wilson, Department of Work and Income solicitor with responsibility for conjugal status policy (the author, Wellington, 5 July 2000).

49 These seem to mirror the "key positive features" identified by Blanchard J in Ruka: cohabitation, companionship, financial interdependence (see the quote accompanying $\mathrm{n} 34$ ).

50 Core Topics, above n $47,8.2123$.

51 "Guidelines For Section 63(b) Inquiries" in Core Topics, above n 47, Appendix II.

$52 R O A D$, undated.

53 ROAD, above n 52 , s 3.7

54 The opinion was requested by the Department on 4 October 1996 and received 17 October 1996: Interview with Kirsty Wilson, above n 48. The update, entitled "1996 087: Definition of a 'relationship in the nature of a marriage'" ["Update 1996 087"], is still in place at time of writing. A new policy is awaiting approval (see Part III B 2 below). 
commitment factors, following Thompson. Ruka meant simply that the legal test was "further refined". 55

A summary of the policy update says "the boundaries of this definition have been adjusted". A "mutual commitment to financially support each other when required is a primary factor" and battered woman's syndrome "may lessen the relevance of the traditional indicators". 56

The update outlines the facts in Ruka which, under former policy, would have led to the conclusion that it was a relationship in the nature of marriage, such as the duration, child together, social activities together, moving cities, set against the violence and the lack of financial or other support. It says the Court of Appeal "concluded that the central question was whether there was such a lack of financial interdependence between the parties to the relationship that it could not properly be described as in the nature of a marriage." 57

The update says "physical evidence of joint finances is sufficient to indicate financial interdependence", 58 and gives as examples: joint hire purchase agreements, joint bank accounts, both partners contributing to household expenses. ${ }^{59}$ The Solicitor-General is quoted: "in the absence of any jointly owned property or shared living expenses, a relationship in the nature of marriage could only be said to exist if sufficient evidence of the requisite mutual commitment to financially support can be gleaned from other traditional indicators." 60

According to the update, "the issue is not as simple as whether or not a particular couple can be said to have separate finances"; rather, the "critical question" is whether the parties "have a mutual commitment to financially support each other in the future, if and when the need arises, and to the extent that the parties are in a position to provide such support". ${ }^{61}$ Testing this "may require an assessment of a couple's state of mind about the future", as "[e]ven though the parties' finances are entirely separate, it is possible that a

55 Interview with Kirsty Wilson, above n 48.

56 Update 1996 087, above n 54, ss 1.1-1.3.

57 Update 1996087 , above n 54, s 2.5.

58 Update 1996 087, above n 54, s 3.1.2.

59 However, Appeal Authority decisions show "physical evidence" is not necessarily sufficient; the Authority is willing to hear credible reasons for joint finances. See Part IV.

60 Update 1996087 , above n 54, s 3.1.2.

61 Update 1996 087, above n 54, s 3.1.3. 
couple might still have the commitment to provide each other with financial support." 62 This may interpret a little too broadly the statement in Ruka that a commitment to support the other partner "must amount to a willingness to support, if the need exists". ${ }^{63}$ The Department's interpretation could apply to a couple who are not financially interdependent, but realise they may one day, "in the future", be sufficiently committed to support each other financially. The emphasis in Ruka seems to be more on present willingness to support. Ruka refers to financial support being "available", and an "acceptance" 64 to support (paying expenses as they arise), which is more concrete, and easier to prove, than a commitment to provide support in the future. ${ }^{65}$

Consistent with $R u k a,{ }^{66}$ absence of support is not genuine if it is "motivated by the knowledge that the dependent partner will then be able to claim a benefit." 67 A refusal to support "would need to be looked at in the context of the relationship as a whole", and "it might be concluded that a refusal to provide financial support was merely a sham" if "all or most of the other indicators of a relationship in the nature of a marriage were found to be present." 68 Officers are directed to "consider past, present and future behaviour". For example: "who has paid which expenses traditionally, and if one of the children required urgent medical attention tomorrow, who would meet the cost?"

The update emphasises the "battered woman" aspect of Ruka, even "to the point where the decision in Ruka might have been misinterpreted as applying only where battered woman's syndrome was present". ${ }^{69}$ The update says the syndrome is not a defence, and "there would need to be reasonably compelling evidence", but it "should be taken into account when considering the normal factors relevant to whether there is a relationship in the nature of marriage". For example, a beneficiary may be living under the same roof "out of fear and helplessness", or sexual intercourse may be coerced. ${ }^{70}$

62 Update 1996 087, above n 54, s 3.1.4

63 Ruka, above $\mathrm{n} 1,161$ per Blanchard J.

64 Ruka, above n 1, 161 per Blanchard J.

65 See Part V for discussion of problems associated with "willingness" to support.

66 Ruka, above $\mathrm{n} 1,161$ per Blanchard J.

67 Update 1996 087, above n 54, s 3.1.8.

68 Update 1996 087, above n 54, s 3.1.8.

69 John Hughes "Battered Woman's Syndrome and 'Interdependence' as Factors in Establishing Conjugal Status in Social Security Law" (1999) 7 Waikato LR 104, 127-128.

70 Update 1996 087, above n 54, s 3.1.8. 
In addition to the policy update, the Department responded by urging a change to the law to lessen the impact of Ruka. The Social Security (Conjugal Status) Amendment Bill (1997) would have removed the emphasis on financial interdependence, as one of the Department's main concerns is that beneficiaries will arrange their finances so they appear to be separate from those of their partner. The Department no longer actively supports the Bill; it is still on the legislative agenda, but nothing has been done to further it for three years. The Department says, "It appears that the Bill was a legitimate response to concerns which have not eventuated to the extent that they initially appeared they would." 71

\section{Recent changes to Department policy}

The Benefit Control Manual has been revised over the last year. Criticism by commentators that the conjugal status section does not adequately reflect $R u k a$ influenced the Department to rewrite the policy. ${ }^{72}$ A draft chapter, approved by the Department, ${ }^{73}$ is awaiting approval from the Ministry of Social Policy, and should be implemented during 2001.

Steven Price describes the Department's pamphlets, policy manuals and computer systems as containing "nary a trace" of $R u k a$, because the policy includes financial interdependence and emotional commitment "simply as factors in a long list of things". ${ }^{74}$ John Hughes criticised the Department for continuing "to a large extent to apply the preRuka policy ... as if that decision had never been delivered." ${ }^{75}$ These deficiencies probably derive partly from the Department's former practice of circulating policy updates, rather than rewriting the relevant sections of the manual.

The draft chapter notes the phrase "relationship in the nature of marriage" is not defined in the Act, and that "guidance for the interpretation of these terms comes from case law". ${ }^{76}$ Summaries of Ruka, Thompson, and Excell follow.

71 Interview with Kirsty Wilson, above n 48.

72 Another influential factor was the change of government, leading to a push by beneficiary advocacy groups for the manuals to be rewritten: Interview with Kirsty Wilson, above n 48.

73 "Conjugal Status Draft" in Benefit Control Manual (Department of Work and Income, May 2000) ["Draft Chapter"].

74 Steven Price "Winz Policies Ignore Ruka Judgment" (15 February 2000) Evening Post, Wellington, New Zealand.

75 "Battered Woman's Syndrome and 'Interdependence' as Factors in Establishing Conjugal Status in Social Security Law", above n 69.

76 Draft Chapter, above n $73,42$. 
The summary of Ruka outlines the salient facts. It quotes from three parts of Blanchard J's judgment: (1) emphasising the importance of financial interdependence and "sufficient features evidencing a continuing emotional commitment"; (2) comparing the "key positive features" of most legal marriages (cohabitation, companionship, emotional commitment), noting that "[w]here these are found together with financial interdependence there will be such a merging of lives as equates for the purposes of the legislation to a legal marriage"; and (3) describing battered woman's syndrome as a factor to be considered.

The summary of Thompson quotes Tipping J's ten physical aspects, and notes that the "ultimate question will always be one of fact and degree." The "mental ingredient" - a commitment by the parties "for the foreseeable future" to their relationship - must also be considered. The summary of Excell quotes Fisher J's core elements.

The draft chapter then sets out Department policy. For people who are not legally married, "it must be shown that there is both: a degree of companionship demonstrating an emotional commitment; and financial interdependence" ${ }^{77}$ Echoing $R u k a{ }^{78}$ it continues: "The commitment must go beyond mere sharing of living expenses, as platonic flatmates or siblings living together may do; it must amount to a willingness to support if the need exists, as well as a degree of companionship demonstrating an emotional commitment." Further, "from the legislation and case law we can see that when considering whether a relationship is 'in the nature of marriage' there are a number of indicators we can use to determine the situation." The indicators are listed as: ${ }^{79}$

Direct financial interdependence such as joint bank accounts or assets or joint loans/credit;

Willingness to support if the need exists;

Mutually agreed financial arrangements;

Emotional commitment and support for each other;

Joint decision making and plans together;

Period of the relationship;

Sharing of one dwelling (full time, part time);

Sharing of one bedroom;

A sexual relationship;

Sharing of parental obligations;

Sharing of household activities;

Sharing of companionship/spare time;

Sharing of leisure and social activities;

77 Draft Chapter, above n 73, 46.

78 Ruka, above $\mathrm{n} 1,161$

79 Draft Chapter, above n 73, 46. 
Presentation to outsiders as a couple;

A relationship exclusive of others.

In comparison, legally married couples who reside in the same place would find it "difficult (though not impossible) ... to substantiate a claim that they are 'living apart' for the purposes of section 63(a)". ${ }^{80}$ Regarding a legally married person as living apart from their spouse requires a physical separation and a "mental acceptance" by one or both of the parties that "the marriage, as an emotional bond, is over." 81 If they reside separately, "an assessment of the indicators used for unmarried people can be used to determine their conjugal status for benefit purposes." ${ }^{12}$ These indicators help establish whether the "mental acceptance" exists. Unlike de facto relationships, financial interdependence is relevant but not essential. ${ }^{83}$

As in the update, the draft chapter reiterates that a "refusal to support, or an arrangement that support will not be given ... motivated by the knowledge that the dependent partner will then be able to claim a benefit" will not "create a genuine absence of financial support." ${ }^{84}$ This also applies to legal marriages.

Evidence which shows whether the indicators are present can be obtained from interviews with the person and the alleged partner, "giving them the opportunity to explain the situation" (unless they refuse to be interviewed), and statements from "witnesses such as landlords, neighbours, friends, family and other acquaintances." 85 Documentary evidence might include: tenancy agreements; bank records; credit or loan documents; public records; hire purchase agreements; school enrolment forms; local authority records; birth or marriage registration; vehicle and property registration; club memberships. ${ }^{86}$

In addition to the revised policy, a new information booklet for beneficiaries was published recently. ${ }^{87}$ It aims to explain $R u k a$ in lay terms:

80

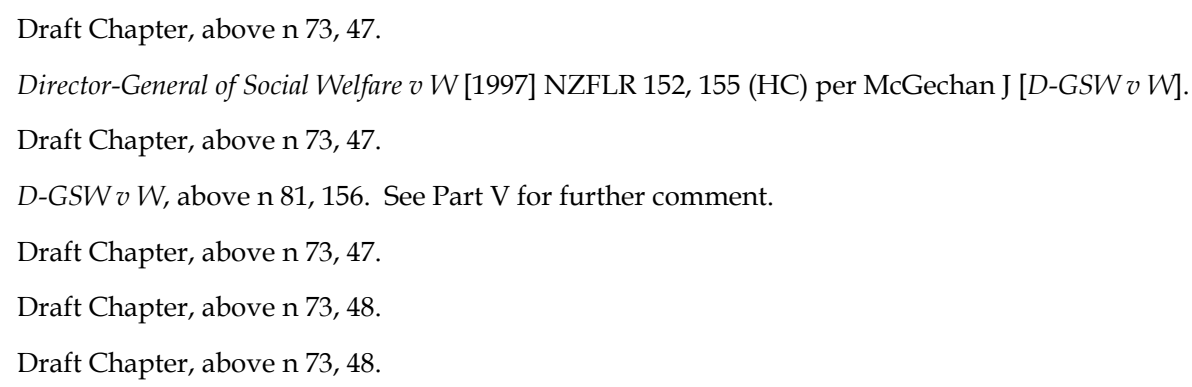


If you share your life with someone of the opposite sex in a way that is 'like marriage', you're in a relationship. You're in a relationship that's 'like marriage' if you and your partner are committed to each other emotionally and have a financial interdependence with each other.

To help applicants determine the status of their relationship, questions referring to the traditional indicators are set out. The booklet also says "You can't use your income support just to become financially independent of your partner while you're in a relationship", but notes that if an applicant is "thinking about leaving a violent relationship, we may be able to give you extra financial help".

In sum, financial interdependence and emotional commitment are now emphasised as the two main components of the policy, with the other traditional indicators still relevant. Although the policy update issued after Ruka noted the importance of financial interdependence, its interpretation of "willingness to support" was potentially misleading. Moreover, it did not replace former policy. It seems that the Department has taken on board the criticisms of commentators, and has now clarified their conjugal status policy to bring it in line with Ruka.

\section{Policy in practice}

The Department says that in practice financial interdependence and emotional support are the two primary elements, and indicia such as those in Thompson go towards establishing those two elements; "in the end, it is an 'overall assessment' based on the usually unique facts of each case". ${ }^{88}$

People are often more willing to acknowledge emotional commitment, so cases are usually argued on the basis of financial interdependence. The Department looks for willingness to support, that is, the potential to support if the person stopped receiving the benefit. ${ }^{89}$ The Department, therefore, continues to emphasise this notion above actual support. ${ }^{90}$

Factors which show financial interdependence become factors which show emotional commitment, and vice versa. Together the factors "create a picture" ${ }^{91}$ Primary indicators of actual financial support are those things most couples have: joint bank accounts, tenancy agreement in both names, guarantors on hire purchase, gifts unusual in a nonemotional relationship (such as a car). Also, the beneficiary might give their status as "de

\footnotetext{
88 Interview with Kirsty Wilson, above n 48.

89 Interview with Kirsty Wilson, above n 48.

90 See Part V for discussion of problems associated with "willingness" to support.

91 Interview with Kirsty Wilson, above n 48.
} 
facto" on hospital forms or finance applications. The Department generally considers that couples should not be seen as de facto in some areas and not in others.

Domestic violence as a factor negating a relationship in the nature of marriage is seen by the Department as problematic, because the Court in Ruka said violence amounting to battered woman's syndrome could negate emotional commitment, but did not rule on the issue because it was not argued on appeal. Furthermore, it is difficult to determine when a relationship reaches that point.

A further complication arises with domestic protection orders as a means of establishing a violent relationship. A beneficiary may be living with a partner for the purposes of the Domestic Violence Act 1995, while claiming a benefit on the basis that they are not living in a relationship in the nature of marriage. This was alluded to as a potential problem in the minority judgment in $R u k a .{ }^{92}$ In my view this is not necessarily problematic, as the Domestic Violence Act expressly covers relationships which are not "partner" relationships. ${ }^{93}$ The Social Security Appeal Authority has rejected the Department's argument that a domestic protection order could "amount to a concession that the close relationship or domestic relationship" was in the nature of marriage. ${ }^{94}$ Further, as the majority in Ruka noted, the phrase may be defined differently in other legislative contexts. ${ }^{95}$

Department officers learn about policy on a six week induction course. Conjugal status forms a small part of the total training, as there is much material to be covered. ${ }^{96}$ Officers have access to the Benefit Control Manual and MAP, the online manual, together with the advice of Department solicitors. Service centre managers could be expected to understand the test in Ruka, but frontline staff would know the basic indicators of a relationship in the nature of marriage. There are practical difficulties in ensuring policy is applied properly, as the Department has 5000 employees. ${ }^{97}$

The Department would prefer beneficiaries to explain their situation if unsure of their conjugal status. Presently, the Department's approach is to trust a beneficiary's assessment of their conjugal status unless and until the Department has reason to suspect they are living in a relationship in the nature of marriage.

92 Ruka, above $\mathrm{n} 1,165$ per Henry J.

93 See the definition of "close personal relationship", Domestic Violence Act 1995, s 4.

94 Decision 19/2000 (16 February 2000) (Latham, McKelvey, Tukukino), 4.

95 Ruka, above $\mathrm{n} 1,162$ per Blanchard J; 183 per Thomas J.

96 Interview with Kirsty Wilson, above n 48.

97 Interview with Kirsty Wilson, above n 48. 
The Benefit Control Unit is responsible for investigating allegations that a beneficiary is living with a partner. Sharing of information between the police and the Department can lead to an investigation, as the partner may be prosecuted for an unrelated crime, and give their address as that of the beneficiary.

Department officers have wide powers to ask for information, and there is a duty on every person (such as neighbours and bank staff) to answer questions put to them. ${ }^{98}$ Department officers have no automatic powers to search, but they can obtain a search warrant which would be executed by and with the police.

Where the Department believes a beneficiary has been overpaid but is not guilty of fraud (that is, they have not deliberately misled the Department as to their conjugal status), or there are mitigating circumstances, repayment is sought under section 86 of the Social Security Act. ${ }^{99}$ The beneficiary's conjugal status must be proved on the balance of probabilities. If the Department believes a beneficiary has been overpaid as a result of fraud, they may take one or both of two options. They may seek repayment and a penalty under section 86 , where the beneficiary's conjugal status and the fraud must be proved on the balance of probabilities. ${ }^{100}$ Alternatively and in addition, the Department may bring a criminal prosecution under section 127 , where the beneficiary's conjugal status and the fraud must be proved beyond reasonable doubt. In both civil claims and criminal prosecutions, the burden of proof is on the Department.

\section{SOCIAL SECURITY APPEAL AUTHORITY DECISIONS SINCE RUKA}

The general approach of the Social Security Appeal Authority, indicated by decisions since $R u k a$, is to consider the sort of indicia set out in Thompson, and make an "overall assessment". Ruka is taken into account, but somewhat unevenly.

In their first decision relating to section 63(b) delivered after Ruka, the Authority said Excell and Thompson "culminated in the decision of the Court of Appeal in Ruka". ${ }^{101}$ They continued: "Various indicia ... have been propounded and in particular, Tipping J in Thompson has listed 10 of such matters. We mention some as far as being applicable to this case". ${ }^{102}$ The Authority notes the extent to which the parties lived in the same house; had

98 Social Security Act 1964, ss 11, 12

99 According to Kirsty Wilson, above n 48: "Repayment is sought under all circumstances. The Department rarely seeks reparation orders as its ability to recover by deduction from benefit and bank accounts is far reaching".

100 The standard of proof was established in Director-General of Social Welfare v Ilyes [1997] NZAR 292 $(\mathrm{HC})$.

101 Decision 108/96 (5 November 1996) Social Security Appeal Authority (Latham, Dell, Morgan) 3.

102 Decision 108/96, above n 101, 3-4. 
a sexual relationship; gave each other emotional support and companionship; socialised together; shared responsibility for children and domestic tasks; and shared "costs and other financial resources by pooling all resources or otherwise". ${ }^{103}$ As the hearing was prior to Ruka, "[1]ittle was said as to financial dependence or sharing"; nevertheless, the Authority concludes that "there was little, if any, sharing of financial resources and certainly not to the extent we would expect of a married couple." The Authority then seems to decide the appeal on the basis of the Thompson approach: ${ }^{104}$

Thus while on the indicia we have identified there are some matters that perhaps could be said to count both ways, ... we think that the proper course after considering the indicia is to stand back and look at the situation as a whole. In doing just that we are unable to conclude that the parties were living together in a state of marriage. The negative aspects as it were, outweighing the positive ....

It is understandable that a decision delivered one month after $R u k a$, where the appeal was heard prior to Ruka, does not strictly follow Ruka. However I would argue that, in general, this continues to be the Authority's approach.

In the next appeal post-Ruka, the Authority said: ${ }^{105}$

[T] he Courts have laid down a number of indicia from which the inference can be drawn that two people are living in a state of marriage. It is not necessary for the Department in any case to prove all the indicia so listed, but to establish several and enough to give rise to that inference. ... [In Ruka] [ $\mathrm{t}$ ]he Court of Appeal acknowledged the practice of listing certain indicia, but laid emphasis on one factor that has always, to the Authority's knowledge, been regarded as one of the indicia ... that is the financial interdependence of the two persons. In addition, the Court of Appeal stressed that there must be either direct evidence or by inference of a commitment between the two of a sharing for a significant time in the future, not necessarily a permanent "till death us do part" sort of commitment, but at least to the point that the commitment would remain for an indefinite period in the future.

Nonetheless, the Department's approach was to "lead evidence to prove certain of the indicia that have been listed", and to invite the Authority to "draw the inference" that the parties were "living in a state of marriage". ${ }^{106}$ The Authority said, "Not one of these matters standing alone would enable that inference so to be drawn, it is the cumulative

103 Decision 108/96, above n 101, 4.

104 Decision 108/96, above n 101, 5.

105 Decision 22/97 (29 January 1997) Social Security Appeal Authority (Latham, Dell, Morgan) 2-3.

106 Decision 22/97, above n 105, 3. 
effect of several that is sought and should be relied upon."107 Allowing the appeal, it was the appellant's credible rebuttal of the Department's evidence that meant the "cumulative effect" of the evidence was insufficient to establish a relationship in the nature of marriage. 108

By contrast, in a decision delivered two months later, the Authority clearly applied Ruka. ${ }^{109}$ The hearing took place shortly before Ruka, and the Authority reserved their decision until after Ruka, to receive further submissions. ${ }^{110}$ The Authority said the "essential matters" in Ruka ("financial interdependence and a commitment, one to the other, although perhaps not a commitment 'till death us do part'") were lacking: ${ }^{111}$

There was no sharing of resources and no contribution made by [him] towards the household. In view of the importance placed upon this aspect by the Court of Appeal, we are compelled to hold, in the light of the Ruka decision that there was no "state of marriage" ... notwithstanding some acknowledged sexual activity ... which we think was a case of [his] taking what he wanted and going.

In another decision, the Authority considered two relationships of the appellant, and found the first to have been in the nature of marriage (they had a sexual relationship, he supported her financially, photographs showed a "happy family unit", and three years together indicated sufficient commitment). ${ }^{112}$ In this relationship the "aspects mentioned in Ruka" were "satisfied", that is, "financial independence"113 (the Authority must mean interdependence) and a "commitment for the future". 114 The Authority says: "Viewed therefore as a whole and without seeing the necessity to traverse the indicia raised in Excell and/or Thompson but having those in our minds, we have come to the conclusion that the Department has proved on the balance of probabilities that there was a state of marriage". 115 However the second relationship was found to be "with more of a sugar

107 Decision 22/97, above n 105, 3 .

108 Decision 22/97, above n 105, 5.

109 Decision 42/97 (26 March 1997) Social Security Appeal Authority (Latham, Dell, Morgan).

110 The Authority notes that the Department's further submissions were "less than helpful": Decision 42/97, above $n 109,3$.

111 Decision 42/97, above n 109, 3-4. The overpayment was cancelled by the Authority, and the appellant appealed against conviction for benefit fraud: $R v$ Knight [1998] 1 NZLR 583 (CA).

112 Decision 91/97 (9 July 1997) Social Security Appeal Authority (Latham, Dell, Morgan) 5.

113 Decision 91/97, above $\mathrm{n} 112,4$.

114 Decision 91/97, above n 112, 5.

115 Decision 91/97, above n 112, 5. 
daddy than a partner"116 (they lived together briefly, had a non-exclusive sexual relationship, had two overseas holidays together, and he gave her $\$ 15,000$ to buy a house).

Much depends on the credibility of the appellant and the quality of the evidence, as exemplified by Decisions 92/97117 and 106/98, ${ }^{118}$ which concern the same relationship but have different results: in the former, he was found to have been living in a relationship in the nature of marriage, while in the latter, she was not. In Decision 92/97, the Authority did not regard the male appellant as credible. They said the "most important factor in our view is the question of financial independence"119 (again, they must mean interdependence). The parties had bought a house as tenants in common, and he gave her his bankcard, with which she made supermarket purchases. The Authority found there was "sufficient evidence to satisfy the test of financial independence as formulated in Ruka in that it was more than simply a case of sharing expenses as would happen in say a joint flatting situation but in the real sense the appellant was paying towards the household out of that bank account."120 Further, "As was said in Excell, at the end of the day one must stand back and look at all circumstances including after $R u k a$, in particular, the financial circumstances". ${ }^{121}$ In Decision 106/98 the Authority heard much more evidence from the female appellant, and found that any financial interdependence was in fact insufficient, and that there was no emotional commitment. The pair had three children together, but their sexual relationship was infrequent, he was away most of the time, and there was no evidence of socialising together. So, "looking at the matter as a whole, the evidence falls short of establishing that the parties were living in a state of marriage". ${ }^{122}$

Evidence of financial support (such as paying bills) is not fatal to the appellant's case if it is found to have been for the benefit of the children, ${ }^{123}$ or that one partner has acted as guarantor on a hire purchase application if they did so because the other had a bad credit rating. ${ }^{124}$ Conversely, minimal evidence of financial support may be sufficient. In

116 Decision 91/97, above n 112, 6.

117 Decision 92/97 (21 July 1997) Social Security Appeal Authority (Latham, Morgan).

118 Decision 106/98 (25 November 1998) Social Security Appeal Authority (Latham, Dell, Morgan).

119 Decision 92/97, above n 117, 4.

120 Decision 92/97, above n 117, 5.

121 Decision 92/97, above n 117, 5.

122 Decision 106/98, above n 118, 7.

123 For example, Decision 72/99 (27 July 1999) Social Security Appeal Authority (Latham, Dell).

124 Decision 36/2000 (15 March 2000) Social Security Appeal Authority (Latham, McKelvey, Tukukino). 
Decision $8 / 2000$, the appellant relied on a lack of financial commitment and cited Ruka. The Authority thought: ${ }^{125}$

the evidence relating to financial support by [him] is not great [it appears he and his family provided money for the child] but we think that there was some such support [and] when that is combined with the other factors which the Department relied upon [statements by the appellant that they lived as a "family"], which we accept, we are constrained to hold on the balance of probabilities that they did and were living in a state of marriage ...

In Decision 17/2000, the Authority noted that the majority in Ruka held that financial interdependence is the "crucial factor", but (quoting $R u k a$ ) it must be "accompanied by sufficient features showing a continuing emotional commitment". ${ }^{126}$ The Authority set out the ten indicia from Thompson, and found that "in terms of the list of indicia to which we have referred, the parties were living in a state of marriage"; 127 further, "[t]aken as a whole we think that the Department has proved [the relationship] on the balance of probabilities". 128

The Authority seems to narrow the application of Ruka in one decision. They are "mindful" of Ruka and "of the importance placed by the majority ... [on] the financial position but we do remind ourselves that Ruka was a criminal case and it was further complicated by the 'battered wives syndrome'."129

A non-exclusive sexual relationship is a common factor in undermining the existence of a relationship in the nature of marriage. The Authority has said it "demonstrates that there was no commitment ... to the appellant as a partner. ... [H]e was leading the double life as it were [which] ... derogates from the concept of marriage as being a one man one woman relationship."130

125 Decision 8/2000 (25 January 2000) Social Security Appeal Authority (Latham, Dell, McKelvey) 4 (emphasis added).

126 Decision 17/2000 (16 February 2000) Social Security Appeal Authority (Latham, McKelvey, Tukukino) 2; Ruka, above n 1, 161 per Blanchard J.

127 Decision 17/2000, above n 126,7 .

128 Decision $17 / 2000$, above $\mathrm{n} 126,8$.

129 Decision 19/2000 (16 February 2000) Social Security Appeal Authority (Latham, McKelvey, Tukukino) 4 .

130 Decision 69/2000 (24 May 2000) Social Security Appeal Authority (Latham, McKelvey, Tukukino) 4. 
Decision 86/2000 concerns section 63(a), a determination that a legally married couple were "living together". Neverthless, it gives insight into Department interviewing methods: ${ }^{131}$

[T] he record of the interview [19 March 1999] does indicate something of a tendency on the part of the investigators to simply ask questions which were focussed on obtaining answers to prove that the appellant was living with her husband in accordance with a list of indicia rather than a more general discussion to determine the nature of the relationship ... .

The Authority, therefore, does apply $R u k a$, principally by noting that the financial aspects of the relationship are of particular significance. Factors which might indicate financial interdependence assume greater or lesser importance depending on the other "indicia" of the relationship, which is consistent with Ruka. ${ }^{132}$

The clearest trend to emerge in the Authority decisions, however, is the "broad value judgment" approach advocated in Excell ${ }^{133}$ and endorsed by the minority in Ruka. ${ }^{134}$ The Authority tends to base its ultimate decision on an "overall assessment" of the relationship, exemplified by this statement: "We think with Fisher J [in Excell] that at the end of the day one should stand back, look at the whole of the evidence and make a decision". ${ }^{135}$ This approach is not referred to by the majority in Ruka, but may be reconciled with the notion of the parties "so merging their lives". ${ }^{136}$ I will now argue that the requirement for financial interdependence is problematic, and suggest that the notion of the parties "so merging their lives" may be more helpful in determining a relationship in the nature of marriage.

\section{PROBLEMS WITH RUKA}

The definition of de facto relationships in the context of social security has generated considerable controversy, including press comment, academic debate, and court appeals. Determining whether a beneficiary is living in a relationship in the nature of marriage involves government officials investigating the intimate relationships of some of the state's more vulnerable citizens. Moreover, the decision has grave consequences for the

131 Decision 86/2000 (10 July 2000) Social Security Appeal Authority (Wallace, McKelvey, Tukukino) 8. This decision was made with a different chairperson, and is significantly longer than most of the decisions.

132 See Blanchard J's statement in the quote accompanying n 32.

133 Excell, above n 2, 248.

134 Ruka, above n 1, 167 per Henry J.

135 Decision 75/97 (3 June 1997) Social Security Appeal Authority (Latham, Dell, Morgan) 7.

136 Ruka, above n 1, 162 per Blanchard J; 185 per Thomas J. 
beneficiary, as recognised by the Appeal Authority. They have stressed "the need for careful investigation in issues of this nature because the step of cancellation of a benefit is a very serious issue for the beneficiary", so the discretion "has to be exercised ... with the utmost care". ${ }^{137}$ Therefore it is desirable that the law be certain, and not based on personal opinion or a "merely intuitive" application of the law. ${ }^{138}$

To a degree Ruka does clarify the law in this area, as it provides a test for de facto relationships in the social security context. John Hughes argued several years earlier that the "economic" aspects of a relationship should be an essential consideration, ${ }^{139}$ and so approves of the emphasis on financial interdependence in Ruka. He suggests that Ruka "accurately reflected the purpose of the principle underlying the marital status rule in social security", and "set out a clear and workable test."140

I would submit that the test in Ruka is not so workable, and may be illusory, because it is still up to the decision-maker to accord weight to the evidence and credibility of witnesses, typically on an "overall assessment" basis. Although the focus on financial interdependence is logical given that the Act is concerned with providing financial assistance for people who need it, "financial interdependence" involves conceptual difficulties.

The requirement in Ruka that financial interdependence "must amount to a willingness to support, if the need exists"141 is problematic. This is a concern because it has become the Department's focus, and has been endorsed recently by the Court of Appeal in $R v$ Batt. ${ }^{142}$ One of the grounds of appeal in Batt was this statement by the trial Judge: ${ }^{143}$

[I]t appears that Mr Vercoe did not have to support Mrs Batt, because she was of course receiving a benefit. Conversely, it appears that Mrs Batt did not have to support Mr Vercoe, because for most of the period in question he was apparently working.

137 Decision 135/97 (17 December 1997) Social Security Appeal Authority (Middleton, Dell, Morgan), 9.

138 Atkin, above n 4, 18.

139 John Hughes "Domestic Purposes Benefit: Lessons from the Furmage Case" [1979] NZLJ 32.

140 "Battered Woman's Syndrome and 'Interdependence' as Factors in Establishing Conjugal Status in Social Security Law", above n 69, 144.

141 Ruka, above n 1, 161 per Blanchard J.

$142 R v$ Batt (3 August 2000) Unreported Court of Appeal CA 47/00 per Tipping, Heron, Williams JJ. Paragraph numbers refer to a version from Brooker's website: <http://www.brookers.co.nz/legal/judgments/Default.asp?doc=2000ca047.htm> (last accessed 18 August 2000).

$143 R v$ Batt, above $\mathrm{n} 142$, quoted in para 24. 
The appellant argued this created an "inevitable inference" that "had either party not been able to support themselves an obligation of support from the other would have come into play". ${ }^{144}$ The Court of Appeal disagreed. The Judge was "simply indicating that there was no occasion in which the support issue was put to practical application or test". ${ }^{145}$ I would suggest that in most cases where a person receives a benefit they will not need the support of a partner, so naturally it will not be put to the test, regardless of whether their relationship is in the nature of marriage. The approach seems circular and does not help to clarify the issue.

As noted above, ${ }^{146}$ the emphasis in Ruka seems to be on actual financial support, or an identifiable acceptance that support will be provided when necessary. In Ruka a constant and deliberate unwillingness to provide support, even though there was a clear need, meant there was no financial interdependence. The Department's approach could mean many more types of relationship are in the nature of marriage, as the factors which show emotional commitment (which people more readily acknowledge) can be used to show the potential or willingness to support financially if the need arose (that is, if the benefit were stopped). ${ }^{147}$ Some people in "boyfriend-girlfriend relationships" would help out financially if the need arose, though it would be a distortion to describe their relationship as being in the nature of marriage.

Further, it may be difficult to ascertain whether a couple have deliberately separated their finances to obtain a benefit, or if they want to keep their finances separate for ideological or personal reasons. A couple may be emotionally committed but separate their finances because they do not wish to be financially committed to each other. John Hughes calls this a "catch 22" for beneficiaries: "If they pool resources to any degree this is prima facie evidence of the existence of a de facto relationship; if they consciously avoid pooling resources they may be regarded as merely attempting to 'influence external appearances'." 148

If one partner refuses to support the other, "motivated by the knowledge that the dependent partner will then be able to claim a benefit", 149 it seems unfair that the

$144 R$ v Batt, above n 142, para 25.

$145 R$ Batt, above n 142, para 25.

146 See Part III B 1.

147 In Batt the Court said "[i]n the end willingness to provide financial support must be an inference drawn from the interdependence of the relationship itself", above n 142, para 18.

148 "Domestic Purposes Benefit: Lessons from the Furmage Case", above n 139, 38.

149 As referred to in Ruka, above n 1, 161 per Blanchard J. 
dependent partner cannot rely on either their partner or the state for financial support. This is likely to impact disproportionately on women (especially with dependent children), who make up the vast majority of appellants.

It seems inconsistent that financial interdependence is not an essential consideration for legally married couples. ${ }^{150}$ They are "deemed to have assumed [financial] responsibility" for each other, while in de facto relationships it "must exist in fact before it can be said that the relationship is one in the nature of marriage". ${ }^{151}$ Section 63(b) enables the Department to treat a beneficiary as married, even though the beneficiary has no legal means of forcing their partner to support them. As stated in Ruka, "for married persons financial obligations are not voluntary: the dependent spouse has some right to maintenance". ${ }^{152}$ It appears contradictory that the relationship is treated as being in the nature of marriage when the vital aspect of a legal marriage (in the context of social security), the legal right to maintenance, is in fact lacking.

Emotional commitment may be less problematic conceptually than financial interdependence, and has been described as a "more sustainable option". ${ }^{153}$ As Judge Shaw said, "to simply view the physical aspects of the relationship and draw an inference from those is to take a naive approach to the complex and subtle dynamic which makes up a commitment between two people". 154 However, it is hard to see how a focus on emotional commitment could avoid the "overall assessment" approach, which seems ultimately to be based on an intuitive impression.

In my view, the concept of the parties "so merging their lives" should take priority over financial interdependence. It was mentioned in Thompson ${ }^{155}$ and appears in both the majority judgments in Ruka. ${ }^{156}$ Combined with an overall assessment of the relationship's tangible features (the "indicia") and the emotional commitment, this approach might provide a more accurate picture of the relationship.

150 See $D-G S W v W$, above $\mathrm{n} 81$.

151 Ruka, above n 1, 182 per Thomas J.

152 Ruka, above n 1, 162 per Blanchard J. Each party is liable to maintain their spouse during and after marriage in certain circumstances (see the Family Proceedings Act 1980, ss 63, 64).

153 Elisabeth McDonald "A Relationship in the Nature of Marriage" [1996] NZLJ 423, 424.

154 Department of Social Welfare v Te Mounanui (18 March 1996) Unreported District Court Henderson Registry.

155 Thompson, above n 3, 374.

156 Ruka, above $\mathrm{n} 1,162$ per Blanchard J; 182, 185 per Thomas J. 


\section{CONCLUSION}

John Hughes argues that in Ruka the Court of Appeal "radically redefined the concept of 'de facto' marriage for social security purposes". ${ }^{157}$ I would suggest that Ruka was not so radical, neither in its potential nor actual impact. The Appeal Authority decisions illustrate the infinite variety of human relationships, and it may be too simplistic to attempt to narrow the test to financial interdependence; the additional requirement of emotional commitment allows the real nature of the relationship to be considered, but it also means that the factors set out in Thompson retain their importance. Ruka certainly made the financial aspect of a relationship the dominant factor, but this approach is problematic.

Perhaps, in the end, the best way to determine whether a relationship is in the nature of marriage is to consider the various factors set out in the case law, to see if there is a sufficient degree of emotional commitment, and to make an "overall assessment" as to whether the parties have "so merged their lives" that their relationship can be equated with a legal marriage. In the context of social security, it is crucial that the applicant or beneficiary does in fact need the support of the state, regardless of the presence or quality of their relationship.

It has taken almost four years for the conjugal status policy and practice of the Department of Work and Income to be revised fully to reflect the law in Ruka more accurately. The new draft chapter on conjugal status, and the informational material available to applicants, represent a significant improvement, as they set out the principles in Ruka much more clearly.

What is not so clear, however, is whether applying Ruka in practice makes much difference to beneficiaries. In the Appeal Authority's "overall assessment" approach, evidence sufficient to amount to financial support or emotional commitment in one situation is insufficient to indicate a relationship in the nature of marriage in another situation. This may owe more to the fact that human relationships are too complex and variable to define satisfactorily, than to the adequacy or otherwise of legal tests, social security policy, and the approaches of decision-makers.

157 "Battered Woman's Syndrome and 'Interdependence' as Factors in Establishing Conjugal Status in Social Security Law", above n 69, 104. 